\title{
MODELS FOR ESTIMATING THE ABOVEGROUND BIOMASS OF HALOXYLON AMMODENDRON IN MINQIN, CHINA
}

\author{
TANG, C.-W. ${ }^{*}$-WANG, R. - LI, C.-L. - LU, G.-C. \\ School of Environmental and Municipal Engineering, Lanzhou Jiaotong University, Lanzhou \\ 730070, Gansu, China \\ (phone: +86-139-1906-5396) \\ *Corresponding author \\ e-mail: cuiwent73@mail.lzjtu.cn
}

(Received 25 $5^{\text {th }}$ Dec 2020; accepted $18^{\text {th }}$ Mar 2021)

\begin{abstract}
To improve the natural environment of arid and desert areas and to protect sand vegetation, we take estimation of the aboveground biomass of Haloxylon ammodendron in the Liangucheng National Reserve as our research object in this study, using SPSS and Excel software for data analysis and processing. Models for estimating aboveground biomass in sandy and gravel soil were established, and the results showed that this value for $H$. ammodendron was significantly correlated with basal diameter and plant height, as well as their complex variables. The best estimation models in sandy and gravel soil are $\mathrm{W}=0.138(\mathrm{DH})^{1.397}$ and $\mathrm{W}=0.189(\mathrm{DH})^{1.433}$, which have prediction accuracies of $82.825 \%$ and $83.688 \%$ and average relative errors of $14.392 \%$ and $13.455 \%$, respectively. These models have high fitting precisions and can be used to estimate the biomass of $H$. ammodendron.
\end{abstract}

Keywords: desert vegetation; estimation models; Liangucheng National Reserve; sandy soil; gravel soil

\section{Introduction}

Land desertification is one of the ten global environmental problems (Temidayo, 2015; Edward et al., 1998). Desert ecosystems are distributed in arid regions, with few species of animals and plants and a fragile ecological environment. The total area of arid and semi-arid land in the world is $5.17 \times 10^{7} \mathrm{~km}^{2}$, about $70 \%$ of which is threatened by desertification (Cheng et al., 2013; Kosmas et al., 2014; Wang and Zhou, 2018). In China, desertified land is mainly distributed in the northwestern part of the country, having an area of $2.61 \times 10^{6} \mathrm{~km}^{2}$. This comprises about $27.2 \%$ of the total national land. The degraded ecosystem in desert regions, which has become one of the major ecological/environmental problems in western China, exerts a negative impact upon economic and social development (Xu et al., 2019; Bian, 2011; Han et al., 2013; Hao, 2017).

Plants are important in desert ecosystems. We can learn about the productivity and environmental quality of such ecosystems by assessing plant biomass, which reflects the total amount of organic matter accumulated by the plant community within a certain time. Research on biomass can help us better understand the landscape structure and function of the vegetation community and the current situations of desert communities as well as the ecological environment (González-Paleo and Ravetta, 2018; Yin et al., 2018). Constructing a biomass-estimation model to reduce field work and avoid environmental damage has become a major method for estimating biomass (Zhang et al., 2014; Fan et al., 2011). Models for estimating the aboveground biomass of desert plants have been extensively studied in recent years. The aboveground biomass and biomass of stems of Haloxylon ammodendron in 3 ecotypes (sand, salt, and gravel) of the Gurbantongut Desert were investigated, and fitted estimation models were 
established (Song and $\mathrm{Hu}, 2011$ ). Alberto Búrquez and Angelina Martínez-Yrízar established a biomass-estimation model for plant communities in three habitats (plain, dry valley, and hillside) of the Sonoran desert (Búrquez and Martínez-Yrízar, 2011). There have been some studies of the biomass-allocation patterns and estimation models of 5 desert-dominant shrubs in Western Ordos, Inner Mongolia (Dang et al., 2017).

Haloxylon ammodendron, which has good drought resistance, is a desert plant adapted to the mid-temperate desert climate. It is also an important tree species for windbreaking and sand fixation in arid regions because of its developed roots. It belongs to the category of secondary protected plants. Minqin, located in the blownsand area of northwestern China, is a source of sandstorms. The ecological environment of this region is currently facing a grim situation due to its location and climate. Although environmental conditions are suitable for $H$. ammodendron, there are few natural plants in Minqin. In order to combat desertification and sandstorms, Haloxylon was introduced from Xinjiang by the government of Minqin beginning in the mid1960s. People have paid greater attention to the cultivation and protection of Haloxylon following the establishment of the Liangucheng National Reserve; it also plays an important role in improving the fragile ecological environment of Minqin and its surrounding areas, reducing natural disasters, and maintaining ecological balance ( $\mathrm{Li}$ and Liu, 2018; Chang et al.,2008; Ma and Wei, 2003).

Many scholars have studied the situation of $H$. ammodendron in Minqin in terms of such features as population characteristics and soil properties (Zhang et al., 2009, 2018; Chang et al., 2012; Wang et al., 2019); however, little has been written about the estimation of its biomass in this area. In this paper, we take Haloxylon ammodendron as our research object and Liangucheng National Reserve in Minqin, Gansu as our research area. H. ammodendron growing on sandy and gravel soils was investigated. SPSS and Excel software were used to analyze and process the data, and models for estimating the biomass of $H$. ammodendron in different habitats were established. These will be helpful in the further study of desert vegetation in arid areas. The purpose of this article is to protect the desert-vegetation community and ecosystem, observe the growth of $H$. ammodendron, and provide basic information for desertification control, ecological restoration, and sustainable development of degraded deserts in the reserve.

\section{General situation in the study region}

Liangucheng National Reserve in Minqin is the largest desert nature reserve in China and the only one in Gansu Province. It is located in the middle of Badain Jaran and the Tengger Desert, around the Minqin Oasis in the northeast of Hexi Corridor, downstream from Shiyang River $\left(102^{\circ} 30^{\prime}-103^{\circ} 57^{\prime} \mathrm{E}, 38^{\circ} 10^{\prime}-39^{\circ} 9^{\prime} \mathrm{N}\right)$. The reserve is divided into three parts: a core region $\left(1,210.6 \mathrm{~km}^{2}\right)$, a buffer region $\left(1,516.6 \mathrm{~km}^{2}\right)$, and an experimental region $\left(1171.6 \mathrm{~km}^{2}\right)$. The total land area is $3,898.8 \mathrm{~km}^{2}$, accounting for a quarter of the area of Minqin (Fig. 1).

The region has an extremely arid continental climate with low rainfall, high evaporation, significant temperature variation, strong winds, and frequent sandstorms. Evaporation exceeds precipitation by 20 times with the annual mean precipitation being $110 \mathrm{~mm}$. Summer and autumn rainfall account for about $80 \%$ of annual rainfall. The annual mean temperature here is $7.7^{\circ} \mathrm{C}$, the extreme low temperature is $-27.3^{\circ} \mathrm{C}$, the extreme high temperature is $39.5^{\circ} \mathrm{C}$, and the average diurnal variation is $14^{\circ} \mathrm{C}$. The 
relative humidity is $45 \%$, there are 137 frost-free days per year, and the maximum depth of frozen soil is $105 \mathrm{~cm}$. The annual average wind speed is $2.4 \mathrm{~m} \cdot \mathrm{s}^{-1}$ and the average annual days of strong wind and sandstorms are 27.4 and 25.9, respectively. The soil texture is generally aridisols which is based on Soil Taxonomy (ST).

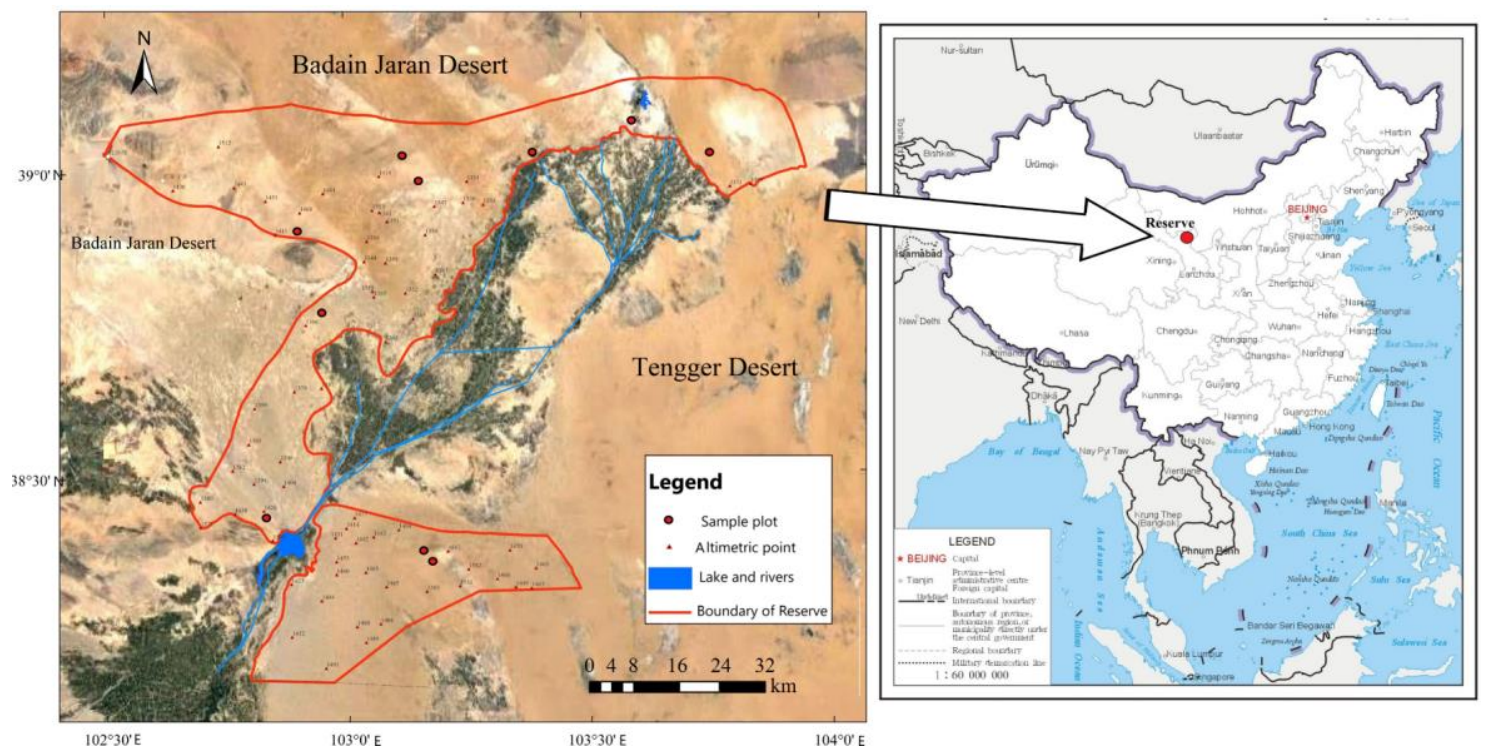

Figure 1. Geographical location map of study area

The vegetation community in the reserve mainly consists of super-xerophytes with obvious zonal characteristics. The major plant types in this area are xerophytes, psammophytes, and halophytes. And the vegetation is mainly composed of perennial herbs, subshrubs, and shrubs. There are two types of vegetation: natural and artificial. The main plant species of local natural vegetation are Calligonum mongolicum, Nitraria tangutorum, Nitraria sphaerocarpa, Artemisia desertorum, Reaumuria songarica, and others. The artificial vegetation includes the forest of Haloxylon ammodendron and Calligonum mongolicum, with Haloxylon ammodendron, Caragana korshinskii, Tamarix chinensis, Hedysarum scoparium, and Calligonum mongolicum as the major dominant species composing the community (Wang, 2003; Song et al., 2003; Ma et al., 2019).

\section{Methods}

\section{Data source}

Field investigation is adopted for this study. Plant samples were collected from sample plots of the reserve in September 2019, and H. ammodendron growing on sandy and gravel soils were investigated. Haloxylon in the reserve is mostly planted artificially. According to the opinions of local researchers concerning the relationship between Haloxylon and the environment, 10 typical vegetation regions $(100 \mathrm{~m} \times 100 \mathrm{~m})$ of Haloxylon ammodendron are randomly selected in the reserve, including 6 regions of sandy-soil habitat and 4 regions of gravel-soil habitat. 5 plots $(20 \mathrm{~m} \times 20 \mathrm{~m})$ were established in each region by five-spot-sampling method and 3-4 plants were randomly selected for investigation in each plot. The height $(\mathrm{cm})$ and basal diameter $(\mathrm{cm})$ of $H$. 
ammodendron were measured, and the plants were harvested and weighed on the spot to obtain the fresh weight $(\mathrm{g})$. The plants were taken back to the laboratory and dried to a constant weight $\left(80^{\circ} \mathrm{C}\right.$ for $\left.48 \mathrm{~h}\right)$, and the dry weight $(\mathrm{g})$ was obtained.

\section{Selecting models}

There are many models for estimating the biomass of trees, and some commonly used variables include basal diameter, plant height, and crown diameter. As a desert plant, $H$. ammodendron grows in sandy areas with strong winds for a long time. Because of the weather and other external conditions, it has a variety of tree shapes, and the crown diameter can easily change greatly. Hence, crown diameter is not suitable for use as an estimation factor in this study. In this paper, SPSS 19.0 and Microsoft Excel 2010 were used for data processing, and information from 7 plants was randomly selected from the data of each habitat for verification of accuracy. Other information was used to establish the estimation models. The independent variables of the models were selected based on statistical analysis of the dry weight (DW), basal diameter (D), plant height $(\mathrm{H})$, and other complex variables $\left(\mathrm{D}^{2}, \mathrm{D}^{2} \mathrm{H}, \mathrm{DH}\right.$, etc. $)$.

To ensure the accuracy of the estimation, three different kinds of equation (linear, linear in two variables, and power function) were used to establish the biomassestimation models of $H$. ammodendron. Such models are commonly used for the biomass estimation of shrubs and small trees (Zhao et al., 2004; Tao and Zhang, 2013). The basic forms of these equations are as follows:

$$
\begin{gathered}
Y=a x+b \\
Y=a_{1} X_{1}+a_{2} X_{2}+\ldots+a_{n} X_{n}+b \\
Y=a x^{b}
\end{gathered}
$$

In the formulas, $\mathrm{y}$ is biomass, $\mathrm{x}_{1}, \mathrm{x}_{2} \ldots \mathrm{x}_{\mathrm{n}}$ are the biomass-related factors, and $\mathrm{a}$ and $\mathrm{b}$ are the undetermined coefficients.

\section{Model evaluation}

After the establishment of the models, they must be evaluated to check whether they meet accuracy requirements and to select the best estimation model. There are many evaluation methods and indicators of the model, including the goodness-of-fit test, residual analysis, and determinant-coefficients analysis. The evaluation indices used in this paper are the correlation coefficient (r), residual sum of squares (RSS), adjusted $\mathrm{R}^{2}$, average absolute value of relative error (RMA), root-mean-square error (RMSE), and prediction precision $(\mathrm{P})$. The calculating formulas are as follows:

$$
\begin{aligned}
& \text { RSS }=\sum_{i=1}^{n}\left(\mathrm{y}_{i}-\hat{\mathrm{y}}_{i}\right)^{2} \\
& \operatorname{TSS}=\sum_{i=1}^{n}\left(\mathrm{y}_{i}-\hat{\mathrm{y}}_{i}\right)^{2}+\sum_{i=1}^{n}\left(\hat{\mathrm{y}}_{i}-\overline{\mathrm{y}}_{i}\right)^{2} \\
& \text { Adjusted } \mathrm{R}^{2}=1-[\mathrm{RSS} /(\mathrm{n}-\mathrm{k}-1)] /[\mathrm{TSS} /(\mathrm{n}-1)] \\
& \mathrm{RMA}=\frac{1}{n} \sum_{i=1}^{n} \mathrm{l}\left(y_{i}-\hat{\mathrm{y}}_{i}\right) / \hat{\mathrm{y}}_{i} \mathrm{I} \times 100 \%
\end{aligned}
$$




$$
\begin{gathered}
\text { RMSE }=\sqrt{\frac{\sum_{i=1}^{n}\left(y_{i}-\hat{y}_{i}\right)^{2}}{n}} \\
\mathrm{P}=\left(1-\frac{\left.\mathrm{t}_{\alpha_{\alpha} \sqrt{\sum_{i=1}^{n}\left(y_{i}-\hat{y}_{i}\right)^{2}}}^{\hat{y}_{i} \sqrt{n(n-m)}}\right) \times 100 \%}{}\right.
\end{gathered}
$$

Here, $y_{i}$ is the measured value, $\hat{y}_{i}$ is the estimated value, $\bar{y}_{i}$ is the average of the measured values, $\mathrm{n}$ is the number of samples, $(\mathrm{n}-\mathrm{k}-1)$ is the $\mathrm{df}$ (degree of freedom) of the residual sum of squares, $(n-1)$ is the $\mathrm{df}$ of the total sum of squares, $\mathrm{m}$ is the number of parameters in the regression model, $(\mathrm{t} \alpha)$ is the $\mathrm{t}$-distribution value for a confidence level of $\alpha(\alpha=0.05)$.

RSS indicates how the degree of the measured values differs from that of the model; the adjusted $\mathrm{R}^{2}$ can reflect the goodness of fit of the regression model and remove the influence of the number of variables. RMA and RMSE can measure the deviation between the estimated value and the measured value; $\mathrm{P}$ can test the estimation effect of the model (Song and Hu, 2011; Xu and Zou, 2004).

\section{Results and analysis}

\section{Selecting variables}

In this paper, correlation analysis of biomass and the indices of Haloxylon ammodendron in different habitats is performed (Table 1). The results show that the aboveground biomass of $H$. ammodendron is significantly correlated with these indices. The correlation coefficient between DW and D of $H$. ammodendron in sandy soil is lower than that in gravel soil; that between DW and H,DH is slightly lower than that in gravel soil (0.003 and 0.011 respectively); the correlation coefficients between DW and $\mathrm{D}^{2}, \mathrm{D}^{2} \mathrm{H}$, and $\left(\mathrm{D}^{2} \mathrm{H}\right)^{2}$ are higher than those in gravel soil. In general, the correlation degrees of biomass and other indices of H. ammodendron in sandy soil are higher than those in gravel soil.

The correlation coefficients between biomass and the indices of Haloxylon in sandy soil range from 0.748 to $0.976\left(\mathrm{D}^{2} \mathrm{H} \& \mathrm{gt}\right.$; $\mathrm{D}^{2} \& \mathrm{gt}$; $\mathrm{DH} \& \mathrm{gt} ;\left(\mathrm{D}^{2} \mathrm{H}\right)^{2} \& \mathrm{gt}$; $\left.\mathrm{D} \& \mathrm{gt} ; \mathrm{H}\right)$, and those in gravel soil range from 0.751 to 0.964 (DH \&gt; D \&gt; $\mathrm{D}^{2} \mathrm{H} \& \mathrm{gt} ; \mathrm{D}^{2} \& \mathrm{gt}$; $\left.\left(D^{2} H\right)^{2} \& g t ; H\right)$. In these two habitats, the highest degrees of interrelation are $D^{2} \mathrm{H}$ and $\mathrm{DH}$, and their correlation coefficients are also in the forefront in the other habitat. For an integrative consideration, $\mathrm{D}^{2} \mathrm{H}$ and $\mathrm{DH}$ are selected as independent variables of the biomass-estimation models.

\section{Establishing biomass-estimation models}

There are the biomass-estimation models for $H$. ammodendron in the form of linear, multiple-linear-regression, and power-function equations (Table 2). The correlation coefficients of the models are all higher than 0.9. We therefore offer our preliminary judgment that the models can be used to estimate Haloxylon biomass. The accuracies for all the models are validated and compared to each other. And the evaluation indices are calculated according to Eq.4-Eq.9. The RSS of the model is all high; this may be due to the large number and values of samples.

The correlation coefficients of the models of Haloxylon in sandy soil are between 0.947 and 0.978. Among the models, the prediction precision $(\mathrm{P})$ and adjusted $\mathrm{R}^{2}$ of 
Model 2 are highest (87.348\%, 0.953) and the RSS and RMSE are smallest. Model 3 has the highest correlation coefficient (0.978) and the smallest RMA. Putting all of this together, Model 2 is the best model for estimating the aboveground biomass of $H$. ammodendron in sandy soil.

Table 1. Correlation analysis of biomass and the indices of Haloxylon ammodendron in different habitats

\begin{tabular}{c|c|c|c|c|c|c}
\hline & $\mathbf{D}$ & $\mathbf{H}$ & $\mathbf{D H}$ & $\mathbf{D}^{\mathbf{2}}$ & $\mathbf{D}^{2} \mathbf{H}$ & $\left.\mathbf{( D}^{\mathbf{2}} \mathbf{H}\right)^{\mathbf{2}}$ \\
\hline Sandy soil & $0.900^{* *}$ & $0.748^{* *}$ & $0.953^{* *}$ & $0.963^{* *}$ & $0.976^{* *}$ & $0.926^{* *}$ \\
Gravel soil & $0.931^{* *}$ & $0.751^{* *}$ & $0.964^{* *}$ & $0.861^{* *}$ & $0.919^{* *}$ & $0.766^{* *}$ \\
\hline
\end{tabular}

Table 2. Estimation models of the aboveground biomass of H. ammodendron

\begin{tabular}{|c|c|c|c|c|c|c|c|}
\hline Habitat & Estimation model & $\mathbf{r}$ & Adjusted $\mathbf{R}^{2}$ & RSS & RMA (\%) & RMSE & $\mathbf{P}(\%)$ \\
\hline \multirow{5}{*}{$\begin{array}{l}\text { Sandy } \\
\text { soil }\end{array}$} & $\mathrm{W}=1.211(\mathrm{DH})-23.716($ Model 1) & 0.959 & 0.915 & 8508.349 & 45.786 & 18.829 & 82.979 \\
\hline & $\mathrm{W}=0.633\left(\mathrm{D}^{2} \mathrm{H}\right)+7.635($ Model 2$)$ & 0.955 & 0.953 & 4700.012 & 27.901 & 13.994 & 87.348 \\
\hline & $\begin{array}{c}\mathrm{W}=0.191\left(\mathrm{D}^{2} \mathrm{H}\right)+0.538(\mathrm{DH})+2.367 \\
(\text { Model } 3)\end{array}$ & 0.978 & 0.952 & 7481.456 & 26.216 & 17.656 & 82.771 \\
\hline & $\mathrm{W}=0.146(\mathrm{DH})^{1.372}($ Model 4$)$ & 0.955 & 0.904 & 7434.171 & 29.327 & 17.600 & 82.825 \\
\hline & $\mathrm{W}=1.895\left(\mathrm{D}^{2} \mathrm{H}\right)^{0.791}($ Model 5$)$ & 0.947 & 0.893 & 12700.418 & 27.019 & 23.004 & 77.987 \\
\hline \multirow{5}{*}{$\begin{array}{c}\text { Gravel } \\
\text { soil }\end{array}$} & $\mathrm{W}=1.598(\mathrm{DH})-18.536($ Model 6$)$ & 0.964 & 0.922 & 3639.759 & 26.832 & 16.124 & 84.931 \\
\hline & $\mathrm{W}=0.826\left(\mathrm{D}^{2} \mathrm{H}\right)+16.432($ Model 7$)$ & 0.919 & 0.831 & 7866.363 & 33.900 & 23.704 & 77.846 \\
\hline & $\begin{array}{c}\mathrm{W}=0.108\left(\mathrm{D}^{2} \mathrm{H}\right)+1.410(\mathrm{DH})-15.157 \\
(\text { Model } 8)\end{array}$ & 0.964 & 0.916 & 3553.483 & 28.203 & 15.932 & 84.375 \\
\hline & $\mathrm{W}=0.189(\mathrm{DH})^{1.433}($ Model 9$)$ & 0.986 & 0.969 & 3987.974 & 17.605 & 16.878 & 83.688 \\
\hline & $\mathrm{W}=2.139\left(\mathrm{D}^{2} \mathrm{H}\right){ }^{0.847}($ Model 10$)$ & 0.981 & 0.959 & 6568.847 & 19.430 & 21.661 & 79.258 \\
\hline
\end{tabular}

The correlation coefficients of the models for estimating $H$. ammodendron biomass in gravel soil are between 0.919 and 0.986 . Model 6 has the highest prediction accuracy (84.931\%), but other indices are in the middle of the five models; the $\mathrm{r}$ and adjusted $\mathrm{R}^{2}$ values of Model 9 are the highest $(0.986,0.969)$, the RMA is the lowest, and its prediction accuracy is only $1.243 \%$ lower than Model 6. By synthesizing these factors, we find that Model 9 is the best biomass-estimation model for H. ammodendron in gravel soil.

\section{Verification and analysis of accuracy}

The relative error reflects the reliability of measurement. The randomly selected Haloxylon data are used for verification and analysis of accuracy and the estimated values of Haloxylon biomass are calculated according to the regression equations. The correlation coefficient and relative error between the estimated and measured values are calculated (Table 3).

The results show that the values estimated by the models were significantly correlated with the measured values, with correlation coefficients between 0.889 and 0.969. The average relative errors of Model 4-Model 10 are small, the model-fitting accuracies are high, and these models can be used to estimate the aboveground biomass of $H$. ammodendron. The average relative errors of Model 1-Model 3 are too large and the estimation accuracies of the results are too low, making them unsuitable for biomass 
estimation. This may be due to the large variation in the water content of $H$. ammodendron sampled from sandy soil, as well as the influence of sampling time, weather, and plant-preservation mode. The accuracies of these models may reach an acceptable limit if the circumstances of the sampling are standardized.

Table 3. Correlation coefficients and relative errors between the estimated and measured values of $H$. ammodendron biomass

\begin{tabular}{|c|c|c|c|c|c|}
\hline Habitat & Estimation model & \begin{tabular}{|l|l|}
$\begin{array}{l}\text { Correlation } \\
\text { coefficients }\end{array}$ \\
\end{tabular} & \begin{tabular}{|c|}
$\begin{array}{c}\text { Average relative } \\
\text { error }(\%)\end{array}$ \\
\end{tabular} & $\begin{array}{c}\text { Relative error } \\
\text { range }(\%)\end{array}$ & $\begin{array}{c}\text { Outlier of relative } \\
\text { errors }(\%)\end{array}$ \\
\hline \multirow{5}{*}{$\begin{array}{l}\text { Sandy } \\
\text { soil }\end{array}$} & $\mathrm{W}=1.211(\mathrm{DH})-23.716($ Model 1$)$ & $0.889 * *$ & 79.217 & $2.660-40.999$ & \multirow{5}{*}{$\begin{array}{l}99.767 \\
97.814\end{array}$} \\
\hline & $\mathrm{W}=0.633\left(\mathrm{D}^{2} \mathrm{H}\right)+7.635($ Model 2$)$ & $0.938^{* *}$ & 30.550 & $9.665-43.962$ & \\
\hline & $\begin{array}{c}\mathrm{W}=0.191\left(\mathrm{D}^{2} \mathrm{H}\right)+0.538(\mathrm{DH})+2.367 \\
(\text { Model 3) }\end{array}$ & $0.912 * *$ & 43.057 & $1.004-42.090$ & \\
\hline & $\mathrm{W}=0.146(\mathrm{DH})^{1.372}($ Model 4$)$ & $0.926^{* *}$ & 14.392 & $0.255-20.025$ & \\
\hline & $\mathrm{W}=1.895\left(\mathrm{D}^{2} \mathrm{H}\right)^{0.791}($ Model 5) & $0.914 * *$ & 17.114 & $1.218-35.144$ & \\
\hline \multirow{5}{*}{$\begin{array}{c}\text { Gravel } \\
\text { soil }\end{array}$} & $\mathrm{W}=1.598(\mathrm{DH})-18.536($ Model 6$)$ & $0.962 * *$ & 15.474 & $1.831-31.716$ & \\
\hline & $\mathrm{W}=0.826\left(\mathrm{D}^{2} \mathrm{H}\right)+16.432($ Model 7$)$ & $0.926^{* *}$ & 9.533 & $4.873-22.046$ & \\
\hline & $\begin{array}{c}\mathrm{W}=0.108\left(\mathrm{D}^{2} \mathrm{H}\right)+1.410(\mathrm{DH})-15.157 \\
(\text { Model } 8)\end{array}$ & $0.960 * *$ & 15.049 & $3.678-28.413$ & \\
\hline & $\mathrm{W}=0.189(\mathrm{DH})^{1.433}($ Model 9$)$ & $0.969^{* *}$ & 13.455 & $4.156-22.735$ & \\
\hline & $\mathrm{W}=2.139\left(\mathrm{D}^{2} \mathrm{H}\right)^{0.847}($ Model 10) & $0.926 * *$ & 15.216 & $2.795-28.463$ & \\
\hline
\end{tabular}

Ps: The relative error range do not conclude outliers

** Significant correlation at 0.01 level

In the two habitats, the correlation coefficients between the estimated and measured values of sandy soil are between 0.889 and 0.938 , and those of gravel soil are between 0.926 and 0.969 . The correlation coefficient and average relative error of the sandy-soil habitat are higher than those of the gravel soil, the relative error range is larger, and there are outliers in the sandy-soil habitat. The relative errors of some plants are far higher than the average level. From the above analysis, we conclude that the fitting accuracy of the biomass-estimation model of the gravel soil is higher than that of the sandy soil.

\section{Analysis and reselection of best-estimate models}

The average relative error of the best biomass-estimation model of $H$. ammodendron in gravel soil is low (13.455\%), making it feasible for use in estimating Haloxylon biomass. However, due to the low fitting accuracies of linear Equations (Models 1-3), Model 4 is chosen as the best biomass-estimation model of $H$. ammodendron in a sandysoil habitat, rather the two other power-function models. The indices of Model 4 are all better than those of Model 5, except for RMA. In conclusion, the best estimation models of sandy soil and gravel-soil habitats are $\mathrm{W}=0.146(\mathrm{DH})^{1.372}$ and $\mathrm{W}=0.189(\mathrm{DH})^{1.433}$, which are both power-function models with $\mathrm{DH}$ as an independent variable.

\section{Discussion and conclusion}

The aboveground biomass of Haloxylon ammodendron was very significantly correlated with basal diameter (D), plant height $(\mathrm{H})$, and their complex variables $(\mathrm{DH}$, $\mathrm{D}^{2} \mathrm{H}$, etc.). In this paper, models for estimating the aboveground biomass of Haloxylon 
ammodendron in sandy and gravel-soil habitats were established with $\mathrm{DH}$ and $\mathrm{D}^{2} \mathrm{H}$ as independent variables. These models included a linear equation, a multiple-linearregression equation, and a power-function equation. The prediction accuracy was between $77.987 \%$ and $87.348 \%$. The power-function equations with DH as an independent variable had the best fitting effect. The best fitting model of the sandy-soil habitat was $\mathrm{W}=0.146(\mathrm{DH}){ }^{1.372}$, with an $\mathrm{r}$ value of 0.955 , adjusted $\mathrm{R}^{2}$ of 0.904 , prediction precision (P) of $82.825 \%$, correlation coefficient between the measured and estimated values of 0.926 , and average relative error of $14.392 \%$. The best fitting model for the gravel-soil habitat was $\mathrm{W}=0.189(\mathrm{DH})^{1.433}$, with an $\mathrm{r}$ value of 0.986 , adjusted $\mathrm{R}^{2}$ of 0.969 , and prediction precision of $83.688 \%$. The correlation coefficient between the measured and estimated values of this model is 0.969 , and the average relative error is $13.455 \%$.

Models for estimating the aboveground biomass of Haloxylon ammodendron in northern China have been studied in recent years. Zhang Hua estimated the aboveground biomass of $H$. ammodendron in the Qingtu Lake at Minqin Qasis, and the best fitting model is $\mathrm{W}=0.8276\left(\mathrm{D}^{2} \mathrm{H}\right){ }^{0.9185}\left(\mathrm{R}^{2}=0.77\right)$ (Zhang et al., 2020). In the Gurbantongut Desert, Song Yuyang established the biomass-estimation models for $H$. ammodendron in three ecotypes (sand, salt, and gravel), the best estimation models are $\mathrm{W}=65.421\left(\mathrm{D}^{2} \mathrm{H}\right)$ $0.8748, \mathrm{~W}=57.754\left(\mathrm{D}^{2} \mathrm{H}\right){ }^{0.8499}$ and $\mathrm{W}=84.409\left(\mathrm{D}^{2} \mathrm{H}\right){ }^{0.7416}$, which have adjusted $\mathrm{R}^{2}$ between 0.9782 and 0.9836 (Song and $\mathrm{Hu}, 2011$ ); the fitted estimation model for $H$. ammodendron of the Gurbantongut Desert established by Tao Ye is $\mathrm{W}=0.3628(\mathrm{CH})$ ${ }^{0.9605}\left(\mathrm{R}^{2}=0.959\right), \mathrm{C}$ is the crown area (Tao and Zhang, 2013). Dang Xiaohong established the biomass estimation model for H. ammodendron in northern edge of the Hobq Desert, the model is $\mathrm{W}=5.27(\mathrm{CH}){ }^{0.794}\left(\mathrm{R}^{2}=0.923\right)$ (Dang et al., 2016).

The power-function equations have the best fitting effect in these studies. This is consistent with the results in this paper, but different areas have different estimation models, which may be due to the vegetation growth condition in different study areas. The variable used in the model of this article was slightly different from that of other studies. Some scholars established models with $\mathrm{D}^{2} \mathrm{H}$ as an independent variable. The model with $\mathrm{D}^{2} \mathrm{H}$ as an independent variable in this paper also achieved a high precision, only slightly lower than that with $\mathrm{DH}$ as an independent variable. Based on the field investigation, there was little difference in the basal diameter of $H$. ammodendron, which made the biomass less affected by basal diameter. It could result from the age of H. ammodendron (mostly less than 15 years). Some scholars selected $\mathrm{CH}$ as a variable to build models. This is due to different vegetation growth conditions and the difficulty in obtaining data. According to the research, the basal diameter of H. ammodendron in Gurbantunggut Desert is mostly very small, and the crown area has higher utility. The base of plant in northern edge of the Hobq Desert is easy to be buried by sand, which makes it difficult to measure the shrub base diameter. In contrast, the plant height and crown width of the shrub are easy to obtain.

Compared with the biomass models obtained by other scholars, $\mathrm{R}^{2}$ of the best fitting model in this study is higher than that of most other models, the accuracy for this model is high. It can be seen from the model-accuracy verification that the correlations between the estimated and measured values of the estimation models were all extremely significant. However, the relative errors fluctuated greatly, except for the models which had excluded, the relative errors of the models for the sandy-soil and gravel-soil habitat were between $0.255 \%-35.144 \%$ and $1.831 \%-31.716 \%$, respectively. The models have limitations in practical applications. To solve this problem, we should obtain data from more sampling points and during different seasons and years. Biomass-estimation 
models of different soil moistures, Haloxylon ages, basal diameters, and the like can also be established to improve the models' prediction ability.

Acknowledgement. The authors gratefully acknowledge the financial supports by the Key R\&D project of science and technology department of Gansu province (18YF1NA015).

\section{REFERENCES}

[1] Bian, Z. (2011): Studies of Desertification Monitoring Methods Based on Remote Sensing Techniques. - Beijing Forestry University, Beijing.

[2] Búrquez, A., Martínez-Yrízar, A. (2011): Accuracy and bias on the estimation of aboveground biomass in the woody vegetation of the Sonoran Desert. - Botany 89(9): 625-633.

[3] Chang, Z. F., Han, F. G., Zhong, S. N., et al. (2008): Self thinning process of Haloxylon ammodendron planted forest in desert area of Minqin. - Acta Botanica BorealiOccidentalia Sinica 28(1): 147-154.

[4] Chang, Z. F., Li, Y. J., Zhang, J. H., et al. (2012): Comparison on functions of wind break and sand fixation four plant species in Minqin desert. - Pratacultural Science 29(3): 358363.

[5] Cheng, L. L., Guo, H., Lu, Q. (2013): Review on the valuation of desert ecosystem service values. - Journal of Desert Research 33(1): 281-287.

[6] Dang, X. H., Gao, Y., Yu, Y., et al. (2016): The biomass estimation models for eight desert shrub species in northern edge of the Hobq Desert. - Journal of Arid Land Resources and Environment 30(5): 168-174.

[7] Dang, X. H., Gao, Y., Meng, Z. J., et al. (2017): Biomass Allocation Patterns and Estimation Model of Five Desert Shrub Species in West Ordos Region. - Journal of Desert Research 37(1): 100-108.

[8] Fan, W. Y., Zhang, H. Y., Yu, Y., et al. (2011): Comparison of three models of forest biomass estimation. - Chinese Journal of Plant Ecology 35(4): 402-410.

[9] Glenn, E., Smith, M. S., Squires, V. (1998): On our failure to control desertification: implications for global change issues, and a research agenda for the future. Environmental Science \& Policy 1(2): 71-78.

[10] González-Paleo, L., Ravetta, D. A. (2018): Relationship between photosynthetic rate, water use and leaf structure in desert annual and perennial forbs differing in their growth. - Photosynthetica 56(4): 1177-1187.

[11] Han, L. Y., Wan, X., Fang, F., et al. (2013): Desertification assessments of Hexi regions in Gansu province by remote sensing. - Arid Land Geography 36(1): 131-138.

[12] Hao, Y. Y. (2017): Evaluation of Ecological Restoration Effects Based on GIS/RS for Northwest Inland River Basin, China. - Lanzhou University, Gansu.

[13] Kosmas, C., Kairis, O., Karavitis, C., et al. (2014): Evaluation and selection of indicators for land degradation and desertification monitoring: methodological approach. Environmental Management 54(5): 951-970.

[14] Li, Z. H., Liu, T. (2018): The relationship between the diversity of a degraded Haloxylon ammodendron community and soil characteristics in the western Gurbantunggut Desert, China. - Chinese Journal of Applied and Environmental Biology 24(5): 1165-1170.

[15] Ma, J. Z., Wei, H. (2003): The ecological and environmental problems caused by the excessive exploitation and utilization of groundwater resources in the Minqin Basin, Gansu Province. - Arid Zone Research 20(4): 261-265.

[16] Ma, J., Shan, L. S., Sun, X. G., et al. (2019): Analysis of land desertification characteristics in Liangucheng National Nature Reserve in Minqin, Gansu Province. Journal of Gansu Agricultural University 54(3): 99-107. 
[17] Olagunju, T. E. (2015): Drought, desertification and the Nigerian environment: a review. - Journal of Ecology \& the Natural Environment 7(7): 196-209.

[18] Song, Y. Y., Hu, X. J. (2011): Estimation models of the aboveground biomass of Haloxylon ammodendron in the different ecotype of Gurbantunggut Desert. - Journal of Northwest Forestry University 26(2): 31-37.

[19] Song, D. M., Xiao, D. N., Zhang, Z. C., et al. (2003): Landscape changes of Minqin oasis in Gansu Province and its driving force. - Chinese Journal of Applied Ecology 14(4): 535.

[20] Tao, Y., Zhang, Y. M. (2013): Multi-scale biomass estimation of desert shrubs: a case study of Haloxylon ammodendron in the Gurbantunggut Desert, China. - Acta Prataculturae Sinica 22(6): 1-10.

[21] Wang, K. (2003): National Nature Reserves in China. - Anhui Science and Technology Publishing House, Hefei.

[22] Wang, X. S., Zhou, Y. Y. (2018): Investigating the mysteries of groundwater in the Badain Jaran Desert, China. - Hydrogeology Journal 26(5): 1639-1655.

[23] Wang, Y. W., Luo, L., Zhang, F., et al. (2019): Soil conservation effect of Haloxylon Ammodendron bushes in Hexi oasis-desert ecotone. - Acta Pedologica Sinica 56(3): 749762.

[24] Xu, D. L., Zou, X. Y. (2004): Statistics. - Central South University Press, Hunan.

[25] Xu, D. Y., Song, A. L., Li, D. J., et al. (2019): Assessing the relative role of climate change and human activities in desertification of North China from 1981 to 2010. Frontiers of Earth Science 13(1): 43-54.

[26] Yin, X. F., Wang, C. G., Zong, Z. Y., et al. (2018): Biomass estimation of desert steppe based on spectral indices along a precipitation gradient. - Spectroscopy Letters 51(7): 324-331.

[27] Zhang, J. C., Wang, J. H., An, F. B., et al. (2009): Population characteristics of natural Haloxylon ammodendron in Minqin, Gansu of China. - Journal of Desert Research 29(6): 1124-1128.

[28] Zhang, J. S., Wang, G., Wang, G. (2014): A review of researches on plant biomass. Journal of Sichuan Forestry Science and Technology 35(1): 44-48.

[29] Zhang, H., Wu, R., Kang, Y. R. (2018): Photosynthetic, physiological, and morphological characteristics of Haloxylon ammodendron assimilation twigs in Minqin Oasis. Pratacultural Science 35(2): 371-379.

[30] Zhang, H., Zhang, Y. H., Zhang, G. G. (2020): Aboveground biomass estimation of the dominant species of vegetation in the Qingtu Lake at Minqin Qasis. - Arid Land Geography 43(1): 201-210.

[31] Zhao, C. Y., Song, Y. D., Wang, Y. C., et al. (2004): Estimation of aboveground biomass of desert plants. - Chinese Journal of Applied Ecology 15(1): 49-52. 